\title{
GROTHENDIECK'S INEQUALITY AND APPLICATIONS
}

\author{
O. I. REINOV
}

Abstract. We give a small survey in connection with the famous Grothendieck's inequality. We consider some classical applications, an application to the geometry of Banach spaces as well as applications to the well known problem of whether the $S_{p}$-algebras with their Schur products should be $Q$-algebras.

Mathematics subject classification (2010): 47B10, 46A32.

Keywords and phrases: $p$-summing operators, $Q$-algebras, James's spaces, Varopoulos problem.

\section{REFERENCES}

[1] A. GRothendieck, Résumé de la théeorie métrique des produits tensoriels topologique, Bol. Soc. Mat. Sao Paulo 8 (1956), 1-79.

[2] R. E. A. C. PAlEy, On the lacunary coefficients of power series, Annals of Math. 34 (1933), 615-616.

[3] G. PISIER, Factorization of linear operators and geometry of Banach spaces, CBMS Regional Conf. Series in Math. 60 (1986).

[4] J. Lindenstrauss, L. TZAFriRi, Classical Banach Spaces I, Springer-Verlag ,I (1977).

[5] A. PelcZYŃski, Banach Spaces ofAnalytic Functions and Absolutely Summing Operators, Amer. Math. Soc, Providence R.I., CBMS 30 (1976).

[6] P. Wojtaszczy , Banach Spaces for Analysts, Cambridge University Press, 1976.

[7] R. C. BLEI, Multidimensional extensions of Grothendieck's inequality and applications, Ark. Mat. 17 (1979).

[8] A. Tonge, The Von Neumann inequality for polynomials in several Hilbert-Schmidt operators, J. London Math. Soc. 18 (1978).

[9] E.D. GLUS KIN, S.V. KISLJAKOV, O.I. REINOV, Tensor products of $p$-absolutely summing operators and right $\left(I_{p}, N_{p}\right)$-multipliers, (Russian) Investigations on linear operators and the theory of functions, IX. Zap. Nauchn. Sem. Leningrad. Otdel. Mat. Inst. Steklov. (LOMI) 92 (1979), 85-102, 319-320.

[10] J. Lindenstrauss, C. STEGALL, Examples of separable spaces which do not contain $l_{1}$ and whose duals are non-separable, Studia Math. 54 (1975), 81-I05.

[11] R. S. JAMES, A non-reflexive Banach space isometric with its second conjugate, Proc. Nat. Acad. Sci USA. 37 (1951), 174-177.

[12] J. WeRMER, Quotient algebras of uniform algebras, in Symposium on function algebras and rational approximation, University of Michigan, 1969.

[13] G. Lumer, États, algèbres quotients et sousespaces invariants, C. R. Acad. Sci. Paris Sér. A 274 (1972), 1308-1311.

[14] N. T. VAropoulos, A theorem on operator algebras, Math. Scand. 37 (1975), 173-182.

[15] N. T. VARopoulos, Some remarks on Q-algebras, Ann. Inst. Fourier 22 (1972), 1-11.

[16] N. T. VARopoulos, On a inequality of von Neumann and an application of the metric theory of tensor products to operator theory, J. Func. Analysis 16 (1974), 83-100.

[17] J. SchUR, Bemerkungen zur Theorie der beschränkten Biliniarformen mit undendlich vielen Veränderlichen, J. Reine Angew. Math. 140 (1911), 1-32.

[18] J. Lindenstauss, A. Pe€ZCińs KI, Absolutely summing operators in $\mathscr{L}^{p}$-spaces and their applications, Studia Math. 29 (1968), 275-326.

[19] A. M. DAVIE, Quotient algebras of uniform algebras, London Math. Soc. 7 (1973), 31-40.

[20] D. P. BLEChER, C. LE MERDY, On quotients of function algebras and operator algebra structures on $l_{p}$, Operator Theory 34 (1995), 315-346. 
[21] C. Le Merdy, The Schatten space $S_{4}$ is a Q-algebra, Proc. Amer. Math. Soc 126 (1998), 715-719.

[22] D. PÉReZ-García, The trace class is a Q-algebra, Annales Academ. Scientiarum Fennic. Mathematica 31 (2006), 287-295.

[23] J. BRIËt, H. Buhrman, T. LEE, T. VIDICK, Multiplayer XOR games and quantum communication complexity with clique-wise entanglement, ArXive: 0911.4007v1 [quant-ph] 20 Nov 2009, 1-25. 